Revista Brasileira de Agricultura Irrigada v.10, nº.6, p. 1065 - 1074, 2016

ISSN 1982-7679 (On-line)

Fortaleza, CE, INOVAGRI - http://www.inovagri.org.br

DOI: 10.7127/rbai.v10n600514

Protocolo 514.16 - 01/12/2016 Aprovado em 22/12/2016

\title{
IRRIGAÇÃO COM ÁGUA SALOBRA NA CULTURA DO RABANETE EM SOLO COM FERTILIZANTES ORGÂNICOS
}

Geocleber Gomes de Sousa ${ }^{1}$, Valdecio dos Santos Rodrigues ${ }^{2}$, Thales Vinicius de Araújo

Viana $^{3}$, Giovana Lopes da Silva ${ }^{4}$, Mário de Oliveira Rebouças Neto ${ }^{5}$, Benito Moreira de Azevedo $^{3}$

\section{RESUMO}

A salinidade é um dos principais fatores ambientais que limitam o crescimento e a produtividade agrícola. Objetivou-se com este trabalho avaliar o efeito do estresse salino no crescimento e na produtividade da cultura do rabanete em solo com e sem biofertilizantes. $\mathrm{O}$ experimento foi realizado na área experimental da UFC, em Fortaleza-CE, no período de setembro a outubro de 2015. O delineamento experimental foi inteiramente casualizado em esquema fatorial $(4 \times 3)$, com cinco repetições. Os tratamentos foram constituídos de quatro valores de condutividade elétrica na água de irrigação, sendo: $0,8 \mathrm{dS} \mathrm{m}^{-1} ; 1,5 \mathrm{dS} \mathrm{m} \mathrm{m}^{-1} ; 3,0 \mathrm{dS} \mathrm{m}^{-}$ ${ }^{1}$ e 4,5 dS m$~^{-1}$ aplicadas em vasos sem biofertilizante (B0), com biofertilizante bovino de fermentação anaeróbio (B1) e aeróbio (B2). As variáveis analisadas foram: número de folhas, área foliar, matéria seca da parte aérea, diâmetro e massa média de fruto e a produtividade. $\mathrm{O}$ biofertilizante bovino de fermentação aeróbia proporciona maiores valores no crescimento do rabanete em relação ao biofertilizante de fermentação anaeróbia e a testemunha em solo sob irrigação com água salobra. A aplicação do biofertilizante bovino de fermentação anaeróbia foi mais eficiente do que o biofertilizante de fermentação aeróbia e a testemunha na redução dos efeitos depressivos dos sais das águas de irrigação na massa média de fruto e na produtividade.

Palavras-chave: Raphanus sativus L., Estresse salino, Biofertilizante.

\section{IRRIGATION MANAGEMENT WITH BRACKISH WATER IN RADISH CROP IN BIOFERTILIZED SOIL}

\footnotetext{
${ }^{1}$ Eng. Agrônomo, Professor Adjunto do curso de Agronomia da Universidade da Integração Internacional da Lusofonia Afro-Brasileira, Redenção, Ceará, Brasil, e-mail: soousagg@unilab.edu.br

${ }^{2}$ Eng. Agrônomo, Mestrando em Engenharia Agrícola pela Universidade Federal do Ceará, Fortaleza, Ceará, Brasil, e-mail: valdeciorodrigues@hotmail.com

${ }^{3}$ Eng. Agrônomo, Professor Associado do curso de Agronomia da Universidade Federal do Ceará, Fortaleza, Ceará, Brasil, e-mail: thales@ufc.br;benitoazevedo@hotmail.com

${ }^{4}$ Eng. Agrônoma, Professora do curso de Engenharia Ambiental e Sanitária da FANOR, Fortaleza, Ceará, Brasil, e-mail: gisolos@hotmail.com

${ }^{5}$ Eng. Agrônomo, Professor do curso de Agronomia do Instituto Federal do Piauí, Campo Maior, Piauí, Brasil, email: agromario@gmail.com
} 


\begin{abstract}
The salinity is one of the main environmental factors that limit growth and agricultural yield. This study was aimed at evaluating the effects of salt stress on radish growth and yield in soil with and without biofertilizers. The experiment was conducted in the experimental area of the UFC, Fortaleza (Ceará), from September to October (2014). The experimental design was that of completely randomized treatments in a (4x3) factorial arrangement, with five replications. The treatments were four levels of irrigation water brackish of electrical conductivity which were: $0.8 \mathrm{dS} \mathrm{m}^{-1} ; 1.5 \mathrm{dS} \mathrm{m}^{-1} ; 3.0 \mathrm{dS} \mathrm{m}^{-1}$ and $4.5 \mathrm{dS} \mathrm{m}^{-1}$ applied in vessels without biofertilizer (B0), with anaerobic biofertilizer (B1) and with aerobic biofertilizer (B2). The following variables were analyzed: number of leaves, leaf area, dry shoot weight, average fruit diameter and average fruit weight and yield. Under saline stress, aerobically fermented bovine biofertilizer provides higher radish growth values as compared to those provided by anaerobically fermented biofertilizer or as compared to those provided by the control treatment. The application of anaerobically fermented cattle biofertilizer was more efficient than the application of aerobically fermented cattle biofertilizer and more efficient than the control treatment in reducing adverse effects of irrigation water brackish on average fruit weight and yield.
\end{abstract}

Keyword: Raphanus sativus L., Salt stress, Input organic.

\section{INTRODUÇÃO}

A cultura do rabanete (Raphanus sativus L.) é uma das hortícolas mais antigas que se tem notícia, havendo registro de que ele seja cultivado há mais de três mil anos. Pertencente à numerosa família das Brassicaceases uma hortaliça anual de porte baixo, originária da Europa, sendo considerada uma opção para o produtor rural, por ser uma das culturas de ciclo mais curto dentre as hortaliças. A sua raiz apresenta-se com um bulbo comestível de cor externa a vermelhada e branca internamente e sabor picante (FILGUEIRA, 2012).

Apesar de ser uma cultura de pequena importância, em termos de área plantada, é cultivada em grande número por pequenas propriedades dos cinturões verdes das regiões metropolitanas (CARDOSO; HIRAKI, 2001). A sua irrigação é realizada com água oriunda de fontes superficiais, sendo utilizado, em alguns casos, água de qualidade inferior, apresentado alto teor de sais dissolvidos (OLIVEIRA et al., 2012).

A cultura do rabanete é classificada como moderadamente sensível à salinidade, apresentando salinidade limiar de 1,2 dS m $\mathrm{m}^{-1}$, para extrato de saturação, e $0,8 \mathrm{dS} \mathrm{m}^{-1}$, para água da irrigação (AYRES; WESTCOT, 1999). Segundo Oliveira et al. (2010) em condições de estresse salino, a cultura do rabanete foi afetada pela área foliar e a massa seca das raízes.

Cabe ressaltar que a salinidade é um dos estresses abióticos que mais afeta o crescimento (SOUTO et al., 2013) e a produtividade das plantas (SANTOS et al., 2012), afetando o potencial osmótico da solução do solo, causando estresse hídrico e provocando efeitos tóxicos nas plantas, que resultam em injúrias no metabolismo e em desordens nutricionais (SOUSA et al., 2010; GOMES et al., 2011).

O uso de água salina na agricultura deve ser considerado como uma alternativa importante na utilização dos recursos naturais escassos na busca por estratégias de manejo que atenue os efeitos negativos para a produção das culturas (DIAS et al., 2012).

Nos últimos anos alguns pesquisadores vêm utilizando biofertilizantes como atenuador do estresse salino no crescimento, desenvolvimento e produtividade das plantas (SOUSA et al., 2012; SILVA et al., 2013). Os biofertilizantes são compostos de resíduo final da fermentação de esterco bovino fresco contendo microorganismos (bactérias, leveduras, algas e fungos filamentosos), podendo ser utilizado na agricultura como 


\section{FERTILIZANTES ORGÂNICOS}

fonte de nutrientes para as plantas (SOUSA et al., 2013; VIANA et al., 2013).

Trabalhos que envolvem o uso de biofertilizante e a salinidade no desempenho produtivo das culturas agrícolas já foram constatado por Dias et al. (2012). Esses autores verificaram que o maracujazeiro amarelo irrigado com águas salinas obteve ganhos significativos de produtividade na presença desse insumo orgânico. Já Silva et al. (2013) também constataram efeitos benéficos do biofertilizante bovino em ambiente salino sobre a produtividade da cultura do feijão-de-corda.

Objetivou-se com este trabalho avaliar o efeito do estresse salino no crescimento e na produtividade da cultura do rabanete em solo com e sem biofertilizantes.

\section{MATERIAL E MÉTODOS}

O experimento foi conduzido em estufa telada na Estação Agrometereológica, CCA, UFC, Campus do Pici, Fortaleza, Ceará, ( $3^{\circ} 45^{\prime}$ 'S; 38 33' W e altitude de $19 \mathrm{~m}$ ). Segundo a classificação de Köppen, a área do experimento está localizada numa região de clima Aw'.

O material utilizado como substrato foi um Argissolo Vermelho Amarelo, apresentando classe textural arenosa, cuja as características física e química estão apresentadas na Tabela 1 , conforme EMBRAPA (1997).

Tabela 1. Características físicas e químicas do solo antes da aplicação dos tratamentos

Profundidade Características do solo

\begin{tabular}{ccccccccccc}
$(\mathrm{cm})$ & $\left(\mathrm{Ca}^{2+}\right.$ & $\mathrm{Mg}^{2+}$ & $\mathrm{Na}^{+}$ & $\mathrm{H}^{+}+\mathrm{Al}^{2+}$ & $\left.\mathrm{Al}^{3+}\right)^{1}$ & $(\mathrm{~K})^{2}$ & $(\mathrm{pH})^{3}$ & $(\mathrm{CEes})^{4}$ & $(\mathrm{PST})^{5}$ & $(\mathrm{DS})^{7}$ \\
\hline $0-20$ & 1 & 0,8 & 0,63 & 1,65 & 0,4 & 0,15 & 7 & 0,54 & 19 & 1,4 \\
\hline
\end{tabular}

${ }^{1}=\mathrm{cmol}_{\mathrm{c}} \mathrm{dm}^{-3 ;}=\mathrm{mg} \mathrm{dm}^{-3 ;}{ }^{3=} \mathrm{H}_{2} \mathrm{O} 1: 2,5 ;{ }^{4}=$ Condutividade elétrica do extrato de saturação $\left(\mathrm{dS} \mathrm{m}^{-1}\right) ;{ }^{5=}$ Percentual de sódio trocável (\%); ${ }^{6}=$ Classe textural; ${ }^{7}=$ Densidade do solo.

O plantio das sementes do rabanete foi realizado em vasos plásticos com capacidade de 25 litros, 0,15 $\mathrm{m}$ de altura e 0,33 $\mathrm{m}^{2}$ de diâmetro, em setembro de 2015. Após o estabelecimento das plântulas, aos 8 dias após a semeadura (DAS), fez-se o desbaste deixando-se uma planta por vaso.

O delineamento experimental foi inteiramente casualizado em esquema fatorial (4 x 3), com cinco repetições. Os tratamentos foram constituídos de quatro valores de condutividade elétrica na água de irrigação, sendo: $0,8 \mathrm{dS} \mathrm{m} \mathrm{m}^{-1} ; 1,5 \mathrm{dS} \mathrm{m}^{-1} ; 3,0 \mathrm{dS}$ $\mathrm{m}^{-1}$ e 4,5 dS m ${ }^{-1}$ aplicada em vasos sem biofertilizante (B0), com biofertilizante anaeróbico (B1) e biofertilizante enriquecido aeróbico (B2).

A quantidade dos sais $\mathrm{NaCl}$, $\mathrm{CaCl}_{2} .2 \mathrm{H}_{2} \mathrm{O}, \quad \mathrm{MgCl}_{2} .6 \mathrm{H}_{2} \mathrm{O}$, utilizadas no preparo das águas de irrigação foi determinada de forma a se obter a CEa desejada na proporção 7:2:1 obedecendo a relação entre $\mathrm{CEa}$ e sua concentração $\left(\right.$ mmol $_{\mathrm{C}} \mathrm{L}^{-1}=\mathrm{CE} \quad \mathrm{x}$ 10) (RHOADES; KANDIAH; MASHALI, 2000).

A irrigação foi iniciada após o desbaste com uma frequência de irrigação diária. O biofertilizante bovino foi preparado a partir de uma mistura de partes iguais de esterco fresco bovino e água não salina $\left(\mathrm{CEa}=0,8 \mathrm{dS} \mathrm{m} \mathrm{m}^{-1}\right)$ sob fermentação anaeróbia, durante 30 dias, em recipiente plástico.

Nesse mesmo período foi preparado o biofertilizante enriquecido com fermentação aeróbia. Foram adicionados 1,4 kg de rapadura moída, 2,8 L de leite, $29,8 \mathrm{~kg}$ de pó de pedra, $10 \mathrm{~kg}$ de calcário dolomítico, 29,8 $\mathrm{kg}$ de gesso, 28,4 L de restos culturais, 1,42 $\mathrm{kg}$ de farinha de osso e 14,2 kg de farinha de trigo. As características químicas dos biofertilizantes podem ser vistos na Tabela 2 . 
Sousa et al.

Tabela 2. Composição de macro e micronutrientes essenciais na matéria seca de biofertilizante (BIO) de fermentação anaeróbia (B1) e aeróbia (B2)

\begin{tabular}{ccccccccccc}
\hline BIO & $\mathrm{N}$ & $\mathrm{P}$ & $\mathrm{K}$ & $\mathrm{Ca}$ & $\mathrm{Mg}$ & $\mathrm{S}$ & $\mathrm{Fe}$ & $\mathrm{Cu}$ & $\mathrm{Zn}$ & $\mathrm{Mn}$ \\
\hline \multicolumn{10}{c}{$\mathrm{g} \mathrm{L}^{-1}$} & \multicolumn{7}{c}{$\mathrm{mg} \mathrm{L}^{-1}$} \\
\hline B1 & 0,3 & 1,1 & 2,3 & 3,2 & 0,3 & - & 43,6 & 0,1 & 7,3 & 6,6 \\
B2 & 0,2 & 0,1 & 0,8 & 4,3 & 0,7 & - & 88,2 & 0,01 & 4 & 0,7 \\
\hline
\end{tabular}

No final do experimento, aos 40 DAS, avaliaram-se as seguintes variáveis: número de folhas totalmente abertas por planta por meio da contagem direta das folhas e área foliar (método do Scanner - utilizou-se um digitalizador de imagens (Scanner), acoplado a um microcomputador, onde a imagem foi analisada pelo software Sigmascan ${ }^{\circledR}$ para a realização do cálculo da área).

Nesse mesmo período as plantas foram colocadas em saco de papel, identificados e colocadas para secar em estufa a $60{ }^{\circ} \mathrm{C}$, até atingirem valor constante de matéria seca. Foi avaliada a matéria seca da parte aérea. Já os frutos foram processados e avaliados o diâmetro através de um paquímetro digital e a massa média de frutos por planta e a produtividade em $\left(\mathrm{kg} \mathrm{ha}^{-1}\right)$ em balança de precisão.
Os resultados foram submetidos à análise de variância e de regressão utilizando-se o programa ASSISTAT 7.6 beta.

\section{RESULTADOS E DISCUSSÃO}

Na análise de variância apresentada na Tabela 3, percebe-se que a interação entre águas salobras $\mathrm{x}$ biofertilizantes, influenciaram significativamente em nível de significância de 1 e $5 \%$ pelo teste $F$ o número de folhas (NF), a área foliar (AF), a matéria seca da parte aérea (MSPA), o diâmetro do fruto (DF), o peso médio de frutos (PMF) e a produtividade (PROD) da cultura do rabanete.

Tabela 3. Resumo da análise de variância para o número de folhas (NF), área foliar (AF), matéria seca da parte aérea (MSPA), diâmetro do fruto (DF), peso médio de frutos (PMF) e produtividade (PROD) em plantas de rabanete em função de diferentes níveis de salinidade, sem biofertilizante, com biofertilizante bovino anaeróbio e aeróbio

\begin{tabular}{cccccccc}
\hline FV & \multicolumn{7}{c}{ Quadrado médio } \\
\hline & GL & NF & AF & MSPA & DF & PMF & PROD \\
\cline { 2 - 7 } Tratamentos & 11 & $5,24^{* *}$ & $77,23^{* *}$ & $0,111^{* *}$ & $80^{*}$ & $344,79^{* *}$ & $4722,55^{* *}$ \\
Salinidade (S) & 3 & $5,16^{*}$ & $62,98^{* *}$ & $0,104^{*}$ & $15,78^{\mathrm{ns}}$ & $211,91^{\mathrm{ns}}$ & $29331,02^{\mathrm{ns}}$ \\
Biofertilizantes (B) & 2 & $0,64^{\mathrm{ns}}$ & $13,82^{\mathrm{ns}}$ & $0,025^{\mathrm{ns}}$ & $60,85^{\mathrm{ns}}$ & $100,75^{\mathrm{ns}}$ & $13944,62^{\mathrm{ns}}$ \\
BxS & 6 & $0,81^{* *}$ & $105,5^{* *}$ & $0,552^{*}$ & $118,49^{*}$ & $492,58^{* *}$ & $68177,63^{* *}$ \\
Resíduo & 36 & 1,25 & 12,96 & 0,334 & 35,43 & 109,9 & 15211,45 \\
Total & 47 & & & & & & \\
MG & & 4,66 & 11,02 & 0,84 & 31,34 & 29,37 & 345,58 \\
CV (\%) & & 23,96 & 30,66 & 29,63 & 18,99 & 25,69 & 25,69 \\
\hline
\end{tabular}

FV= Fonte de variação; $\mathrm{CV}=$ coeficiente de variação; $\mathrm{MG}=$ média geral; $\mathrm{GL}=$ grau de liberdade.

Observa-se na Figura 1, que o modelo linear decrescente foi $o$ que melhor se ajustou para os tratamentos com B0, B1 e B2 com o aumento da condutividade elétrica da água (CEa). No entanto, na menor concentração de sais da água de irrigação a planta emitiu o maior número de folhas na presença do B1, seguido do B0 e do B2. Essa tendência pode ser justificada pelo incremento de nutrientes essenciais presente nesse insumo orgânico, conforme Tabela 1. 


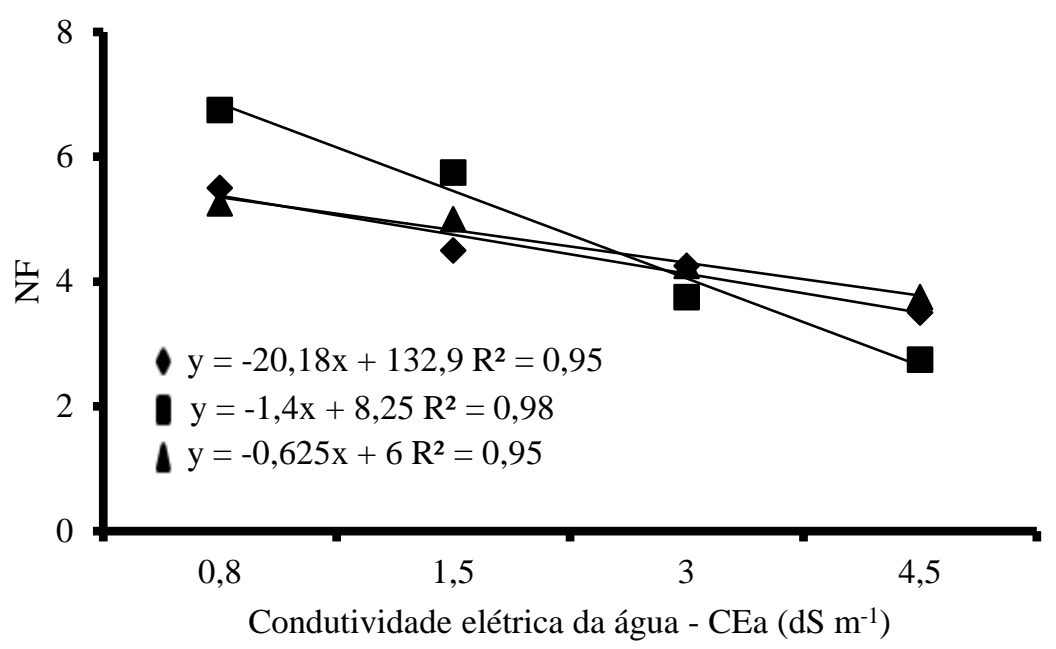

Figura 1. Número de folhas em plantas de rabanete irrigado com águas salobras em solo sem biofertilizante - B0 $(\diamond)$, com biofertilizante anaeróbio - B1 ( • ) e biofertilizante aeróbio - B2

Esses resultados estão coerentes com os apresentados por Yildrim et al. (2008), que observaram cerca de 6,5 folhas por planta com água de irrigação de $1,86 \mathrm{dS} \mathrm{m}^{-1}$. De forma semelhante, Oliveira et al. (2010) registraram um número de folhas de 6,9 em plantas de rabanete irrigadas com água de $0,5 \mathrm{dS} \mathrm{m}^{-1}$. Ainda segundo esses autores nas maiores salinidades (de 3,5 e 5,0 dS m ${ }^{-1}$ ), foram observados os menores valores, 5,5 e 3,6 folhas por planta.

Costa et al. (2014) cultivando amendoim irrigado com águas salinas em solo com biofertilizantes, verificaram uma superioridade do número de folhas na presença desse insumo. Esse efeito positivo do biofertilizante pode estar relacionado à liberação de substancias húmicas no solo, induzindo o aumento do ajustamento osmótico as plantas pela acumulação dessas substancias facilitando a absorção de água e nutrientes em meios salinos (SILVA et al., 2011; AYDIN et al., 2012).

$\mathrm{Na}$ Figura 2 pode-se verificar que $\mathrm{o}$ aumento da salinidade da água de irrigação inibiu de forma linear decréscimo a área foliar para os tratamentos com B0, B1 e B2, porém na presença do insumo as plantas apresentaram maior expansão foliar.

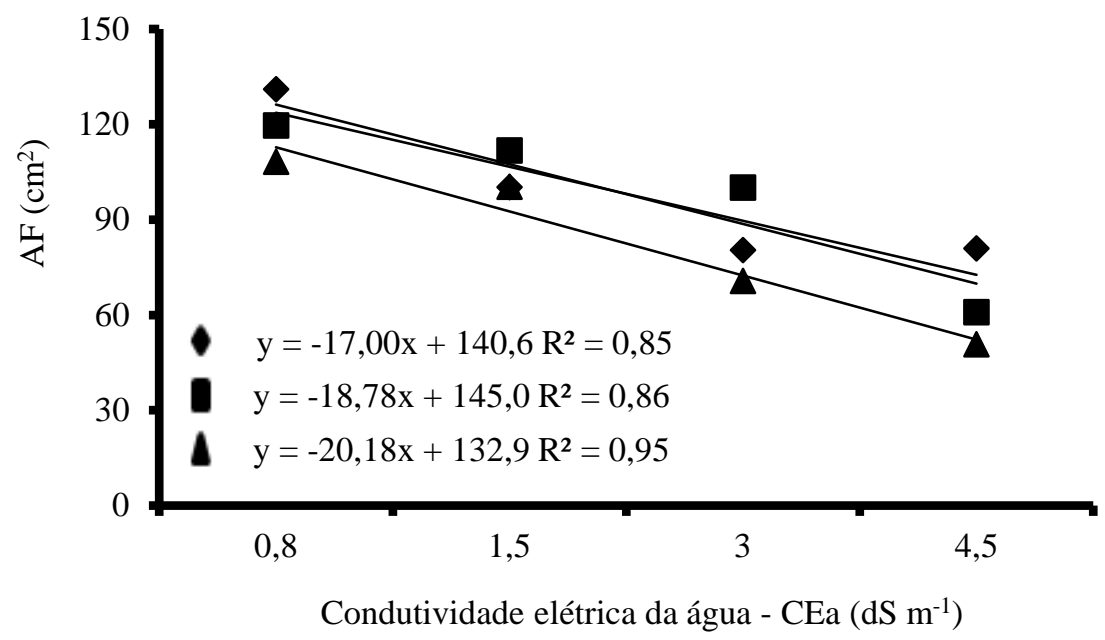

Figura 2. Área foliar de folhas em plantas de rabanete irrigado com águas salinas em solo sem biofertilizante B0 ( $)$, com biofertilizante anaeróbio - B1 ( $)$ e biofertilizante aeróbio - B2 ( $\mathbf{\Delta})$ 
A superioridade da área foliar sob irrigação com água de baixa salinidade evidencia os efeitos expressivos do biofertilizante bovino, resultando em maior eficiência das plantas nos processos fotossintéticos (GOMES et al., 2015). É importante destacar que a redução no crescimento foliar representa um mecanismo de defesa das plantas sob condições de estresse hídrico e salino, reduzindo as perdas de água por transpiração (SILVA et al., 2011).

Resultado similar ao desse estudo foi observado por Jamil et al. (2007), que estudando plantas de rabanete irrigadas com água de alta salinidade $\left(5,47 \mathrm{dS} \quad \mathrm{m}^{-1}\right)$ observaram um decréscimo dos valores de área foliar aos 15 DAS. Do mesmo modo, Oliveira et al. (2010), evidenciaram o mesmo resultado em plantas de rabanete sob estresse salino.

Quando da presença de biofertilizante, os dados estão de acordo com Sousa et al. (2012) ao analisarem o efeito da salinidade da água de irrigação em plantas de milho e por Souto et al. (2013) em plantas de noni.

A matéria seca da parte aérea das plantas decresceu em função do aumento da concentração de sais na água de irrigação e os valores estatisticamente menores foram registrados no B0 seguido de B1 e B2 (Figura 3). Trabalhos que envolvem o efeito do estresse salino na redução de biomassa em olerícolas, já foi relatado por Silva et al. (2013) em berinjela e por Oliveira et al. (2014) em maxixe.

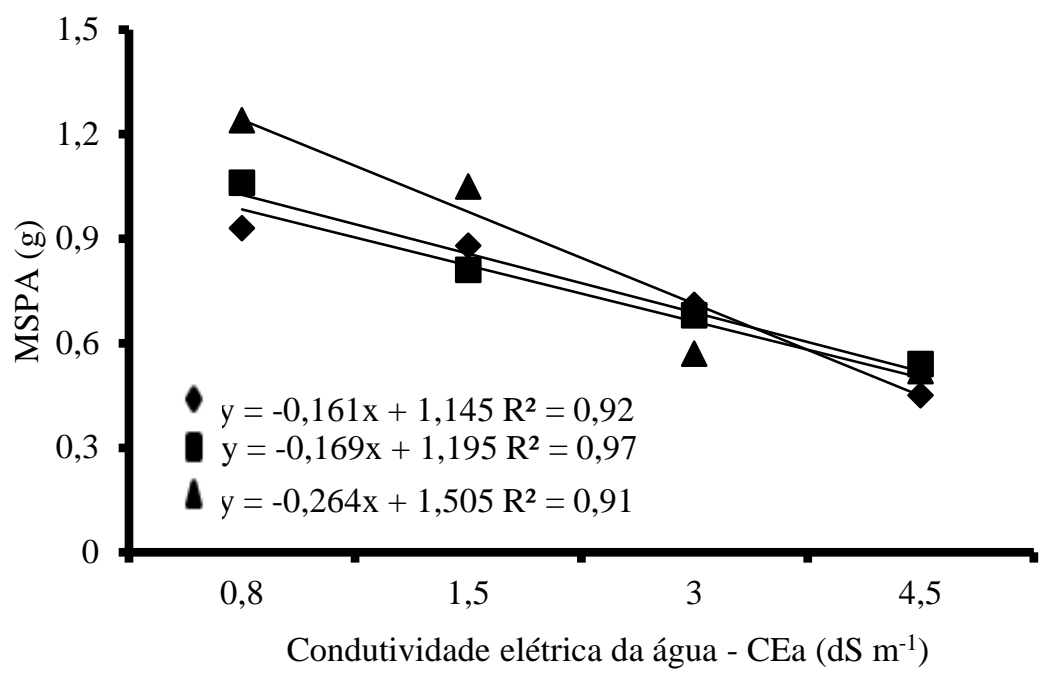

Figura 3. Matéria seca da parte aérea de plantas de rabanete irrigado com águas salobras em solo sem biofertilizante - B0 (^), com biofertilizante anaeróbio - B1 (•) e biofertilizante aeróbio - B2

Salienta-se que mesmo com o aumento do estresse salino a adição do biofertilizante bovino promoveu maior incremento de matéria seca da parte aérea em plantas de rabanete. O efeito positivo dessa fonte orgânica sob essa variável, também foi evidenciada por Silva et al. (2011) na cultura do feijão-de-corda e por Costa et al. (2014) na cultura do amendoim.

O aumento do estresse salino afetou de forma linear decrescente o DMF na presença do biofertilizante de fermentação aeróbio, anaeróbio e na testemunha (Figura 4). É importante ressaltar que o estresse salino pode ir além de uma simples diminuição no potencial hídrico no solo até a injúria celular, causada por um estresse oxidativo na planta (GOMES et al., 2011), sendo que esses efeitos em conjunto pode resultar na redução na qualidade de frutos (SANTOS et al., 2012). 


\section{FERTILIZANTES ORGÂNICOS}

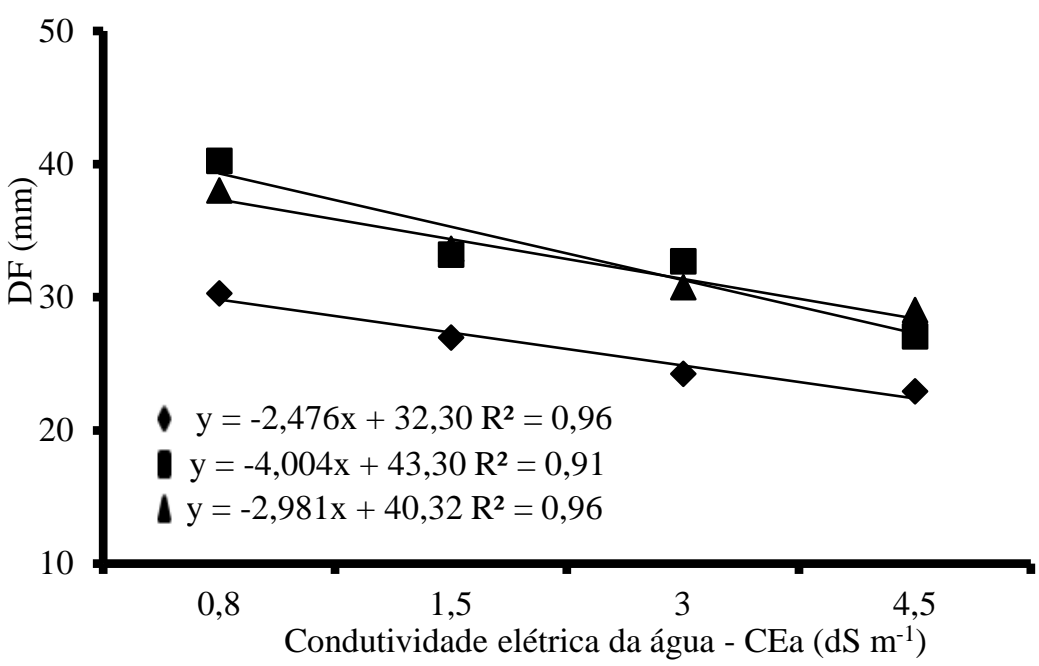

Figura 4. Diâmetro do fruto em plantas de rabanete irrigado com águas salobras em solo sem biofertilizante - B0 $(\star)$, com biofertilizante anaeróbio - B1 ( • ) e biofertilizante aeróbio - B2 ( $\mathbf{\Delta})$

O efeito positivo do biofertilizante pode indicar que a aplicação desse insumo orgânico atenue os efeitos decorrentes da salinidade da água de irrigação em relação às qualidades físicas dos frutos, seja proporcionando aumento nos processos metabólicos (estimulante ou nutricional) ou exercendo efeito sobre os processos de ajustamento osmótico (FREIRE et al., 2010).

A partir das análises de regressão para a MMF em função da condutividade elétrica da água (CEa) sob diferentes tipos de biofertilizantes (Figura 5), verificou-se que o modelo linear decrescente foi o mais adequado para os tratamentos B0, B1 e B2.

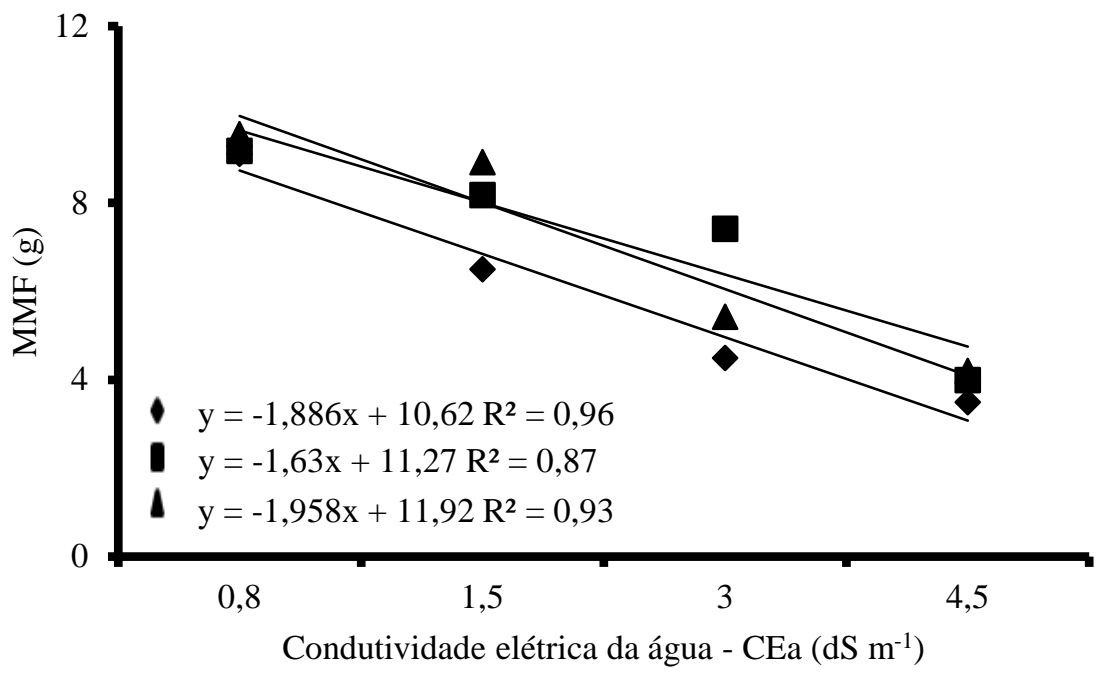

Figura 5. Massa média de fruto em plantas de rabanete irrigado com águas salobras em solo sem biofertilizante - B0 (•), com biofertilizante anaeróbio - B1 ( $\bullet$ ) e biofertilizante aeróbio - B2 ( $\mathbf{\Delta})$

Resultados similares ao desse estudo foi observado por Dias et al. (2012) na cultura do maracujazeiro amarelo, onde segundo esses autores, o MMF diminuiu com o aumento das diferentes condutividades elétricas da água de irrigação associadas às épocas de aplicação de biofertilizante bovino. Por outro lado, Santos et al. (2012) não obtiveram respostas significativas do estresse salino em plantas de pitangueira cultivada em solo com húmus. 
$\mathrm{Na}$ Figura 6, observa-se a interação significativa entre a salinidade da água de irrigação e a aplicação dos biofertilizantes para a produtividade da cultura do rabanete. O B1 e o B2 apresentam valores superiores em relação a testemunha sob as diferentes concentrações de sais da água de irrigação. Essa superioridade pode ser atribuída ao adequado fornecimento de nutrientes essenciais fornecidos pelo biofertilizante (VIANA et al., 2013), bem como de possíveis melhorias nas atividades biológicas do solo (SANTOS et al., 2014).

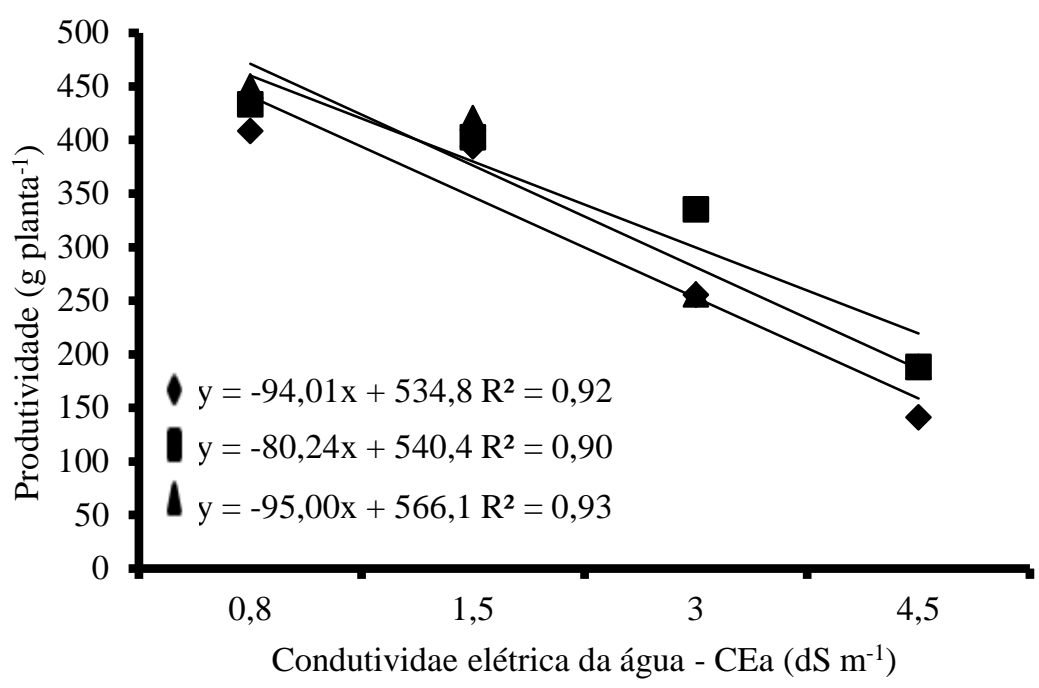

Figura 6. Produtividade em plantas de rabanete irrigado com águas salobras em solo sem biofertilizante - B0 ( $)$, com biofertilizante anaeróbio - B1 ( $\boldsymbol{-})$ e biofertilizante aeróbio - B2 ( $\mathbf{\Delta})$

Estudos que revelam o efeito da interação entre fontes orgânicas para a adubação e salinidade da água de irrigação, foram registradas por Dias et al. (2012). Esses autores avaliando a produção do maracujazeiro amarelo em solo com biofertiliznate e irrigado com água salina, verificaram que o insumo orgânico interferiu positivamente, com superioridade quando aplicado uma semana antes do plantio e a cada 90 dias. Da mesma forma, Santos et al. (2012) e Silva et al. (2013) também obtiveram resultados positivos adubando a cultura da pitangueira e feijão-de-corda, respectivamente, com biofertilizante bovino via foliar e húmus em solo irrigada com águas salobras.

\section{CONCLUSÕES}

O biofertilizante bovino de fermentação aeróbia proporciona maiores valores no crescimento do rabanete em relação ao biofertilizante de fermentação anaeróbia e do que a testemunha em solo irrigado com água salobra.

A aplicação do biofertilizante bovino de fermentação anaeróbio foi mais eficiente do que o biofertilizante de fermentação aeróbio e do que a testemunha na redução dos efeitos depressivos dos sais das águas de irrigação na massa média de fruto e na produtividade.

\section{REFERÊNCIAS}

AYRES, R. S.; WESTCOT, D. W. A qualidade da água na agricultura. 2. ed. Campina Grande: UFPB, 1999. 153 p.

AYDIN, A.; KANT, C.; TURAN, M. Humic acid application alleviate salinity stress of bean (Phaseolus vulgaris L.) plants decreasing membrane leakage. African Journal of Agricultural Research, v.7, n.7, p.1073-1086, 2012.

COSTA, F. R. B.; GOMES, K. R.; SOUSA, G. G.; AZEVEDO, B. M.; MONTEIRO, F. J. F.; 


\section{FERTILIZANTES ORGÂNICOS}

VIANA, T. V. A. Crescimento inicial do amendoinzeiro irrigado com águas salinas em diferentes substratos. Revista Brasileira de Agricultura Irrigada, v.8, n.6, p.466 - 475, 2014.

CARDOSO, A. I. I.; HIRAKI, H. Avaliação de doses e épocas de aplicação de nitrato de cálcio em cobertura na cultura do rabanete. Horticultura Brasileira, v.19, n.3, p.328-331, 2001.

DIAS, T. J.; CAVALCANTE, L. F.; NUNES, J. C.; FREIRE, J. L. O.; NASCIEMNTO, J. A. M. Qualidade física e produção do maracujá amarelo em solo com biofertilizante irrigado com águas salinas. Revista Semina, v.33, suplemento 1, p.2905-2918, 2012.

EMBRAPA - Empresa Brasileira de Pesquisa Agropecuária. Sistema Brasileiro de Classificação de Solos. 2.ed. Rio de Janeiro: Embrapa Solos, 2006. 306 p.

FILGUEIRA, F. A. R. Novo Manual de Olericultura: Agrotecnologia moderna na produção e comercialização de hortaliças. 2. ed. Viçosa: UFV, 2012. 402 p.

FREIRE, J. L. O.; CAVALCANTE, L. F.; REBEQUI, A. M.; DIAS, T. J.; NUNES, J. C.; CAVALCANTE, Í. H. L. Atributos qualitativos do maracujá amarelo produzido com água salina, biofertilizante e cobertura morta no solo. Revista Brasileira de Ciências Agrárias, v. 5, n.1, p.102-110, 2010.

GOMES, K. R.; AMORIM, A. V.; FERREIRA, F. J.; FILHO, F. L.; LACERDA, C. F.; GOMESFILHO, E. Respostas de crescimento e fisiologia do milho submetido a estresse salino com diferentes espaçamentos de cultivo. Revista Brasileira de Engenharia Agrícola e Ambiental, v.15, n.4, p.365-370, 2011.

GOMES, K. R.; SOUSA, G. G.; LIMA, F. A.; VIANA, T. V. A.; AZEVEDO, B. M.; SILVA, G. L. Irrigação com água salina na cultura do girassol (helianthus annuus l.) Em solo com biofertilizante bovino. Irriga, v.20, n.4, p.680693, 2015.

JAMIL, M. REHMAN, S.; LEE, K. J.; KIM' J. M.; KIM' H.; RHA' E. S. Salinity reduced growth PS2 photochemistry and chlorophyll content in radish. Scientia Agricola, v.64, n.2, p.111-118, 2007.

OLIVEIRA, F. R. A.; OLIVEIRA, F. A.; MEDEIROS, J. F.; SOUSA, V. F. L. FREIRE, A. G. Interação entre salinidade e fósforo na cultura do rabanete. Revista Ciência Agronômica, v.41, n.4, p.519-526, 2010.

OLIVEIRA, A. M.; OLIVEIRA, A. M.; DIAS, N. S.; FREITAS, K. K. C.; SILVA, M. K. B. Cultivo de rabanete irrigado com água salina. Revista Verde de Agroecologia e Desenvolvimento Sustentável, v.7, n.4, p.0105, 2012.

OLIVEIRA, F. A.; PINTO, K. S. O.; BEZERRA, F. M. S.; LIMA, L. A.; CAVALCANTE, A. L. G.;OLIVEIRA, M. K. T.; MEDEIROS, J. F. Tolerância do maxixeiro, cultivado em vasos, à salinidade da água de irrigação, Revista Ceres, v.61, n.1, p.147-154, 2014.

RHOADES, J. D.; KANDIAH, A.; MASHALI, A. M. Uso de águas salinas para produção agrícola. Campina Grande: UFPB, 2000. 117p. (Estudos FAO. Irrigação e drenagem, 48).

SANTOS, A. P. G.; VIANA, T. V. A.; SOUSA, G. G.; GOMES-DO-Ó, L. M.; AZEVEDO, B. M.; SANTOS, A. M. Produtividade e qualidade de frutos do meloeiro em função de tipos e doses de biofertilizantes. Horticultura Brasileira, v.32, n.4, p.409-416, 2014.

SANTOS, G. P.; CAVALCANTE, L. F.; NASCIMENTO, J. A. M.; BRITO, M. E. B.; DANTAS, T. A. G.; BARBOSA, J. A. Produção de pitangueira utilizando adubação organomineral e irrigação com água salina. Irriga, v.17, n.4, p.510 - 522, 2012. 
SILVA, F. L. B; LACERDA, C. F; SOUSA, G. G; NEVES, A. L. R; SILVA, G. L; SOUSA, C. H. C. Interação entre salinidade e biofertilizante bovino na cultura do feijão-de-corda. Revista Brasileira de Engenharia Agrícola e Ambiental, v.15, n.4, p.383-389, 2011.

SILVA, F. L. B.; LACERDA, C. F.; NEVES, A. L. R.; SOUSA, G. G.; SOUSA, C. H. C.; FERREIRA, F. J. Irrigação com águas salinas e uso de biofertilizante bovino nas trocas gasosas e produtividade de feijão-caupi. Irriga, v.18, n. 2, p.304-317, 2013.

SOUSA, G. G.; LACERDA, C. F.; CAVALCANTE, L. F.; GUIMARAES, F. V. A.; BEZERRA, M. E. J.; SILVA, G. L. Nutrição mineral e extração de nutrientes de planta de milho irrigada com agua salina. Revista Brasileira d de Engenharia Agrícola e Ambiental, v.14, n.11, p.1143-1151, 2010.

SOUSA, G. G.; MARINHO, A. B.; ALBUQUERUQE, A. H. P.; VIANA, T. V. A.; AZEVEDO, B. M. Crescimento inicial do milho sob diferentes concentrações de biofertilizante bovino irrigado com águas salinas. Revista Ciência Agronômica, v.43, n.2, p.237-245, 2012.
SOUSA, G. G.; VIANA, T. V. A.; BRAGA, E. S.; AZEVEDO, B. M.; MARINHO, A. B.; BORGES, F. R. M. Fertirrigação com biofertilizante bovino: efeitos no crescimento, trocas gasosas e na produtividade do pinhão-manso. Revista Brasileira de Ciências Agrárias, v.8, n.3, p.503-509, 2013.

SOUTO, A. G. L.; CAVALCANTE, L. F.; NASCIMENTO, J. A. M.; MESQUITA, F. O.; LIMA NETO, A. J. Comportamento do noni à salinidade da água de irrigação em solo com biofertilizante bovino. Irriga, v.18, n . 3, p.442-453, 2013.

VIANA, T. V. A.; SANTOS, A. P. G.; SOUSA, G. G.; PINHEIRO NETO, L. G.; AZEVEDO, B. M.; AQUINO, B. F. Trocas gasosas e teores foliares de NPK em meloeiro adubado com biofertilizantes. Revista Brasileira de Ciências Agrárias, v.8, n.4, p.595-601, 2013.

YILDRIM, E. DONMEZ, M. F.; TURAN, M. Use of bioinoculants in ameliorative effects on radish plants under salinity stress. Journal of Plant Nutrition, v. 31, n.12, p.2059-2074, 2008. 